\title{
Bilingualism in Albania and Its Benefits
}

\author{
PhD. Lediana Beshaj
}

Executive Director, Research and Development Institute Wisdom

\section{Doi:10.5901/ajis.2016.v5n3s1p436}

\section{Abstract}

Bilingualism as a phenomenon is becoming more and more prevalent and widespread all over the world. This is encountered in Albania as well, and thus it is considered important to pay some attention to this issue. It is an interesting linguistic phenomenon, which goes unnoticed as we live our daily life as ordinary people. We all are living with the benefits coming from speaking two or more languages. There are several advantages if one is bilingual or multi-lingual and several factors have influenced in having a bilingual society. This research focuses more on the advantages, as from the research conducted in order to shed light to this issue, it is obvious that Albanians have benefited a lot by being bilingual, and definitely the advantages outnumber the disadvantages. To draw conclusions, families bringing up bilingual children were interviewed and the results all show that the benefits are numerous especially in a developing country as Albania is.

Keywords: bilingualism, learning strategy, language acquisition, society, native speaker.

\section{Introduction}

Recently the phenomena of globalization and the people's migration or emigration is ever-increasing; this leads to a mingling of different cultures which is unavoidable. The interaction between cultures brings as a consequence an increasing number of multicultural societies (Hamers \& Blanc, 2000). Hence, due to globalization, these societies have become more diverse and the people of these societies speak more than one language, i.e. they have become multilingual. According to (Grosjean 2010) there have been conducted surveys regarding the multilingual phenomenon which state that more than $60 \%$ of the population in the whole world speaks more than one language in their daily life. It is impressive that up to $70 \%$ of children are being brought up in a bilingual environment (Crystal 1997).

Albania is one of ethnically homogeneous country in the Europe, where the majority of population speaks Albanian and knows another language as well. In addition, it is one of the most polyglot nations in Europe. Italian is widely spoken by Albanians, Greek in the south part of the country, also recently because of many Albanian emigrants living in Italy and Greece, Italian language has become a spoken language by many Albanians. The vast majority of the young generation is interested in learning English and they communicate and understand it to some extent.

Recently, Albania has become a multi - cultural country. Knowing a language means knowing a culture. Many minority groups are living in Albania especially in Tirana, such as Italians, Chinese, whose number is increasing rapidly every day, Americans, a few Germans and many Turkish people. These groups of population belong to different nationalities. Besides the fact that they live in Albania and work here, they have created bilingual families as such as many Italian - Albanian, American- Albanian, Turkish-Albanian families, etc.

In Albania there are many regions where two languages are spoken. In the south, in the region of Saranda, Gjirokastra people know and speak Albanian and Greek fluently. In the middle of Albania in the region of Vlora, Durrësi, people speak Albanian and Italian. In the northern regions in Dibra and they speak Albanian and Macedonian.

However, in Tirana there are many bilingual children as there are many families, where one of the parents is a foreigner. Thus, bilingualism as socio-linguistic phenomenon is widely spread in Albania, and the aim of this research is to display the benefits deriving from being a bilingual.

\section{Research Methodology}

The type of research that is used in this study is quantitative research. It is limited to only some families living in Albania, Turkish-Albanian and American Albanian families. Italian - Albanian, Greek - Albanian All parents are met by a close contact and apart from other questions, questions on the advantages of being bilingual were asked. Apart from the information which is extracted from the respective responses given, when asked the questions from questionnaire, these parents and children were willing to give more details during the long conversations conducted. 


\section{Studies Related to Bilingualism}

It is considered appropriate to mention what is bilingualism in order to have a clear understanding, then to actually delve on the bilingualism issue in Albania.

What is bilingualism?

The concept of bilingualism is discussed by many linguists all over the world. In Bilinguality and Bilingualism book by Josiane F. Harmes and Michel H.A. Blanc "bilingualism" is defined as:

Having or using two languages especially as spoken with the fluency characteristic of a native speaker; a person using two languages especially habitually and with control like that of a native speaker' and bilingualism as 'the constant oral use of two languages'. In the popular view, being bilingual equals being able to speak two languages perfectly; this is also the approach of Bloomfield (1935: 56), who defines bilingualism as the native-like control of two languages (F.Hamers \& Blanc, 2000, p. 6).

Though there are many studies related to bilingualism there are some intricate factors which ought to be taken into account when delving on this issue. The effects of bilingualism present many insinuations which scholars aim to highlight as the compiled information until today cannot display all the complex aspects of bilingualism. However, investigating various perspectives of bilingualism definitely serves as important input in understanding it a little bit better.

There exist a lot of controversies, whether bilingualism influences positively or negatively, but so far many scholars have come to admit the fact that it has a negative effect on some aspects of children's linguistic performance. The children who are brought up bilingually are typically found to possess smaller vocabularies in each of their languages when compared to their monolingual counterparts (as indicated by both productive and receptive measures of vocabulary size), although this disadvantage might disappear when considering conceptual vocabulary or total vocabulary (Junker \& Stockman, 2002; Oller \& Elliers, 2002 Pearson, Fernández, \& Oller, 1995; Petitto \& Kovelman, 2003; Poulin-Dubois et al. 2012).

The starting point of the research studies on the interrelation of bilingualism on one hand and intellect on the other, dates in the 20s and these researches were based on intelligence tests, which were called psychometric. At that time children were not encouraged to acquire two languages at the same time because according to Diaz this was seen as a disadvantage affecting the intellect and the cognitive knowledge of the child as well it would bring language confusion (Diaz, 1983). These statements were supported by facts where bilingual children were seen to encounter a "language handicap" (Diaz, 1983).

Hamers \& Blanc (2000) in their study admit that you cannot draw the right conclusion if you do not take into account the amount of language exposure between the monolinguals and bilinguals. They claim that it is obvious that children who know one language own a more affluent vocabulary than those who know two languages because the monolingual's language knowledge is restricted to just one language (Hamers \& Blanc, 2000).

In 1962 the views on the negative influence that bilingualism had changed with the study of Peal and Lambert, who published the results of their study which strongly emphasized that bilinguals do not face negative aspects of bilingualism related to the cognitive and meta-linguistic development. Their research points to a positive impact and studies to come were mostly observing a positive interrelation between cognitive development and bilingualism. According to Bialystok, these researches have ensured empirical data on the cognitive benefit acquired by bilingual children if it is compared with the other children who are monolingual, especially in assignments which require high cognitive flexibility (Bialystok,1999). Bialystok's study tries to support the claim that bilingual children are capable to sort problems out, which require concentration and differing information (Bialystok, 1999). To get to the conclusion mentioned above Bialystok made a research with sixty children whom were divided into two groups, one group had bilingual children Chinese-English and the other one had monolingual of English. They attended the same school with similar socioeconomic backgrounds. They were given tasks to do, the results showed that the bilinguals displayed better skills than monologists. Hence, this might show that bilingual children are better at solving problems.

\section{Factors Influencing in the Existence of Bilingualism in Albania}

\subsection{Geography}

It relevant to mention that geographical closeness of two communities necessitates the establishment of a good communication in order to have successful trade relationships. Albania borders Greece, Montenegro, Macedonia, Kosovo as well due to the small distance between Italy and Albania the trade is done by sea, which has been very successful so 
far. The members of the two communities have a tendency to study and use each other's languages, which obviously means bilingualism as they use these two languages with native fluency. For instance, the communities of the southern part of Albania know very well the Greek language and vice-versa, so it happens with the other communities close to Macedonia. The largest number belongs to the Greek and Albanian bilinguals, not only because of trade but also because the eastern Adriatic coast did not have good harbors (Igpumenitsa harbor developed after Greece lost Saranda); and the trade by sea was controlled by the Adriatic islands, especially the island of Corfu, which had a great domination. Another reason is related to religious purposes as well as due to immigration or trade. It is displayed a better insight If we take into account, some historical facts where it is stated that:

"the Greeks, of course, are not the only linguistic minority within southern Albania. The Roman conquest has also left its traces. The (traditionally) transhumant Vlachs or Arumani, who speak a Latin language (Arumanian) similar to Rumanian, have long pastured their flocks and engaged in commerce throughout the Pindus range in Albania and Greece. Some Vlachs speak Arumanian and Albanian, some speak Arumanian and Greek, some are trilingual, and some are monolingual, having adopted the state language (Greek or Albanian or Macedonian, etc.). In the nineteenth century, the "Hellenic" faction of some southern Albanian and Macedonian cities was primarily Vlach. Finally, Albanian territory also includes Macedonian-speaking villages. ${ }^{1}$

\subsubsection{Historical factors such as immigration}

Historical events often assess and define a national language. "The most powerful groups in any society are able to force their language upon the less powerful" - (Romaine, 1955: 23). The country has been under the Ottoman empire for 50 Years, then it was invaded by Italian, Serbian, Bulgarian, Austro-Hungarian, Greek, and French forces during World War I and during World war II by Italian (until 1943) and then German forces. Consequently, there are linguistic traces felt in the actual language. There are many Turkish words like: penxhere, tenxhere, kazan, zeherr, etc. Italian words like: nongrata, tavolinë, natë, nona, etc. Some words belonging to the Greek language are: manastir, monopat, farmak, fener, etc.

Furthermore, another important factor which deserves a mention is the unemployment, which led many Albanians to leave the country. After the communist regime the economical situation worsened and unemployment in Albanian cities reached $60 \%{ }^{2}$. Greece, which borders the southern part of Albania, was the only source of income for many Albanians who were willing to work for Greek farms and businesses, even though they were not paid as the Greeks were. Albanian emigrants married Greek partners consequently in their families two languages were spoken, consequently their children faced bilingualism and were brought up bilingually. The same thing happened with Albanians who emigrated in Italy and Germany or elsewhere.

Today, we hear many of their children switching from one language to the other without facing difficulties.

Another issue that can be noted is that if both parents are Albanian, the child speaks the language perfectly, has no difficulty in understanding or communicating because they are surrounded by Albanian people and both parents speak Albanian at home and at school and even in their friendship or community they face the language of the community where they are brought up. Nevertheless, if one of the parents is Albanian and the other is Greek, Italian, German etc. it is noticed a lack of fluency in the Albanian language because the parents when communicating with each other have a tendency to speak the language that both of them find easier. Though, most of them want and try to teach the child the Albanian language. Hence, the child faces difficulties, especially when they have to switch from one language to the other.

\subsubsection{Globalisation}

Globalization has a great impact on bilingualism. Recently, communicating in more than one language is applied very often. People try to communicate worldwide, therefore it is indispensable to know and speak more than one language so that the communication between people is easier and there would not be misinterpretations. It can be stated that English is the language spoken worldwide, it is so in Albania as well, and children start learning it since they are 9 years old. According to the definition above on bilingualism, it can be stated that most of the children in Albania, when they grow up, they possess two languages and are able to speak two languages with the facility of a native speaker. This is also proved 
by various exams they take on English language. Furthermore, it is a prerequisite if they want to apply for a Master's Degree or if they want to continue their studies abroad.

\subsubsection{Different mother tongues}

There are many families in Albania, where one of the parents is Albanian and the other is a foreigner. In this case bilingualism is unavoidable as it is likely that both parents wish to transmit their native tongue to the coming generations. Therefore the child is brought up bilingually.

\subsubsection{Advantages of being raised bilingually}

There are children who have two first languages, who have learned these languages by their parents with different nationalities, but is it a good idea to be raised bilingually? Are there any disadvantages?

Considering the research conducted in order to discover whether it is an advantage to be a bilingual or not, it can be concluded that from the interview with these ten families, who live in Albania, it can be admitted that the advantages outnumber the disadvantages. The advantages that people who live in Albania find are presented below.

The parents of the bilingual children say that their children focus and pay attention when you talk to them, especially when it is about switching the languages, for example in the interview with family one, when the father asks the child to do something and says it in English, the child has a tendency to listen more carefully as they live in Albania and they hear Albanian often.

Many scientific researchers have concluded that a bilingual child who is fluent in two languages has more advantages in life rather than the monolingual child. They say that a bilingual child is more alert and is more predisposed to focus on relevant information and avoid the irrelevant information.

However, Bialystok and Martin-Rhee (2008) made a research on control of attention among French-English bilinguals. Despite low scoring on test on relevant vocabulary bilinguals held more advantage in multi tasks which require control and concentration than those who only speak a language. In addition, Martin-Rhee (2008), claims that some development psychopathologies such as autistic spectrum disorder, deficit disorder are connected with incompetent inhibitory control. So bilingualism is an integral factor to understand children's development processes, it influence certain disorders in a positive way. Being bilingual is an advantage which goes beyond communication. In Canada York University (2004), it has been discovered that people who speak two languages are "mentally sharped", their brain inhales information quickly. Also it prevents mental weakening in coming years. Many researches including Bialystok have revealed that bilingualism is a kind of exercise for brain. Based on Bialystok experience he said: "They can get a little extra mileage from these cognitive networks because they have been enhanced throughout life." (Being Bilingual May Boost Your Brain Power, 2011).

Another advantage is related to the information that the child might search, of course if child is able to read, write, speak or use the computer. Nowadays, technology is inseparable from our life, which somehow helps people solve problems quickly and they can be informed from the news as radio, TV, etc. All these are found in print, electronic or any other media, to access all the information, it is easier for a bilingual or multilingual person compared to another who is a monolingual person and somehow one is limited to have access in all sources. As we know English is used all over the world and the latest news in the field of sciences, politics, economy, education, internet etc. is transmitted in the English language.

What is considered as another advantage is related to the job opportunities that a bilingual person has. Mostly those who are bilingual or multilingual have better chances to be employed as the employers are more interested in employing a person who knows two or more languages and he is not forced to employ a translator.

It is often quoted that "learning a new language means learning new culture". When a person learns a language, it doesn't mean just learning how to communicate and use the grammar appropriately, but learning a new culture as well. Reading about a particular country's history or culture is a good thing but participating, communicating, discussing, sharing ideas in that language in complete a different experience.

\subsection{Disadvantages}

Compared to advantages there are not many disadvantages of being bilingual. One may be language confusion. Some bilinguals confuse both languages, especially grammatical rules. Mostly children are predisposed to do so because it is 
hard enough to keep one language straight. They may speak a different language at school, a different language with friends and a different language at home. In this case the child may get confused; nevertheless this happens during the early stage of the growing up phase. One of the parents from the families interviewed on this issue had a good laugh as she started thinking of the mistakes that her child made because she was confused with the word "ordinary person", which means with no special or distinctive features; normal, whereas in Albanian if you hear "an ordinary person - njeri ordiner" means a bad, vulgar person.

When these children grow up they can tell the difference. Bilingual children may start speaking later compared to monolingual children because they have two meanings of the words, sentence or objects in the mind because in some languages some words may be pronounced the same, but the meaning may be different as in Turkish kurnaz means cunning while in Albanian means stingy.

Based on Bialystik (2010), it can be stated that bilinguals' communicative skills suffer if they are compared to skills possessed by the monolinguals and this is due to the vocabulary. The vocabulary of the bilinguals is spread across two languages (Bialystik, 2010). Nevertheless, it is the child's vocabulary that suffers if the cognitive development is taken into account. Based on Birna Arnbjörnsdóttir's research language confusion can occur in those cases when discrepancies between the two languages emerge or when children cannot attend the educational resources (Birna Arnbjörnsdóttir's 2011). When the child attends school and is faced with a continuous bilingual development then the acquisition of the vocabulary is satisfactory. Another disadvantage is related to the misperception regarding the cultural identity. Switching from one cultural identity to the other can make the child feel comfortless. The child may confuse things up regarding the traditions, behavior, culture which can result in embarrasing situations.

\section{Conclusion}

By studying and interviewing some bilingual families, who are raising their children bilingually, it is hoped to bring a clear picture of the present day situation in Albania regarding bilingualism. Based on their answers, we are able to distinguish whether it is an advantage to be bilingual in Albania or not. The best strategy for raising a bilingual child successfully, it is One-Parent-One-Language strategy. The parents are raising bilingual children because their parents belong to different nationalities and each of them speaks a different language. They speak a different language at home and another language at work or within the community.

What is noted in all the families is that, in the question where they were asked is that they all replied the same; each parent addresses to the child in hislher mother tongue accept in same case where it is necessary to speak the other languages. Also children address their parent in the same language, while children most of the time address each-other in the father's language or the language spoken by community.

Nevertheless, bilingualism is a complex field difficult. As stated in this research paper early investigations claim that bilingualism affects children's language use as well cognitive development in a negative way which results in linguistic deficiency, lower intelligence level and linguistic confusion. Later, Peal and Lambert's research changed these ideas that bilingualism was only represented by the deficiencies mentioned because they conducted a close survey. They indicated a positive cognitive development, better concentration, flexibility in the language use, etc. These positive aspects of bilingualism are noticed from all the parents of the bilingual children who are living in Albania.

\section{References}

Bialystok, E. (1999). Cognitive complexity and attentional control in the bilingual mind. Child Development, 70, 636-644. Crystal, D. (2003). English as a Global Language: Cambridge University Press.

de Abreu, P. M. E. (2011). Working memory in multilingual children: Is there a bilingual effect? Memory, 19(5), 529-537.

Diaz, R. (1983). Thought on two languages: The impact of bilingualism on cognitive development. Review of Research in Education, 10, 23-54. Retrieved from http://jstor.org/stable/1167134

Grosjean, F. (2010). Bilingual: Life and Reality: Harvard University Press.

Hamers, J.F \& Blanc, H.A. (2000). Bilinguality and bilingualism (2nd ed.). New York, NY: Cambridge University Press

Junker, D. A., \& Stockman, I. J. (2002). Expressive vocabulary of German-English bilingual toddlers. American Journal of SpeechLanguage Pathology, 11(4), 381

Romaine, S. (1989). Bilingualism. Oxford: Wiley-Blackwell

Retrieved from: http://www.bbc.co.uk/wales/schoolgate/aboutschool/content/3inwelsh.shtml, accessed on 10 October 2013.

Source: http://www.translationdirectory.com/article419.htm, accessed on 15 October 2013. 